\title{
MODERNIZATION OF THE ESTONIAN NATIONAL GNSS REFERENCE STATION NETWORK
}

\author{
Jaanus METSAR ${ }^{1 \star},{\text { Karin } \mathrm{KOLLO}^{1} \text {, Artu ELLMANN }}^{1,2}$ \\ ${ }^{1}$ Department of Geodesy, Estonian Land Board, Mustamäe rd. 51, 10621 Tallinn, Estonia \\ ${ }^{2}$ Department of Civil Engineering and Architecture, Tallinn University of Technology, Ehitajate rd. 5, \\ 19086 Tallinn, Estonia
}

Received 24 May 2018; accepted 11 June 2018

\begin{abstract}
The first GNSS (Global Navigation Satellite System) CORS (Continuously Operating Reference Station) in Estonia became operational in 1996. Starting from 2008 four Estonian CORS are incorporated into the EPN (EUREF Permanent GNSS Network). During the years 2014-2015 modernization of the GNSS CORS in Estonia was carried out. Currently the total number of the resulting ESTPOS reference stations is 28. These ESTPOS stations were interconnected to the I order national geodetic network by a special GNSS campaign in 2017. The maintenance and compilation of the ESTPOS based research products is explained. Aspects of the ESTPOS usage, including also the real time surveys, are discussed. Comparisons with SWEPOS (Swedish national GNSS CORS) and FinnRef (Finnish national GNSS CORS) networks indicate possibilities for further ESTPOS developments.
\end{abstract}

Keywords: GNSS, CORS, ESTPOS, RTN.

\section{Introduction}

In the 1990-ies GNSS (Global Navigation Satellite System) CORS (Continuously Operating Reference Stations) were pre-dominantly used for establishing continental/ global geodetic networks and monitoring changes in geodetic reference systems. GNSS CORS data series can also be used for quantifying land movements and analysing space weather. Under favourable observation conditions a few millimetres positioning accuracy can be reached with data post-processing. Nowadays the surveying industry uses CORS data also for kinematic applications, e.g. for determining ALS (Airborne Laser Scanning) or MLS (Mobile Laser Scanning) trajectories. Also GNSS real time kinematic (RTK) or RTN (Real Time Network) measurements are widely used for surveys, but also for machine control and mobile robot guidance. With RTN it is rather straightforward, and accurate (within $1 . . .2 \mathrm{~cm}$ ) to carry out geodetic measurements such as topographic/ engineering surveys and less demanding stake out tasks (e.g. Sobak, Ellmann, \& Mill, 2015; Moser, Barišić, Rajle, \& Dimter, 2016). Hence, CORS based services have become a crucial part of modern surveying industry as more and more measurements are solely conducted with using RTN.

In Europe, the geodetic reference frame coordinator is EUREF, which is IAG (International Association of Geodesy) Reference Frame Sub-Commission for Europe (established in 1987). The primary goal for EUREF was to implement the European Terrestrial Reference System ETRS89 across the continent. Estonia joined the EUREF activities in 1992 (Madsen, F. \& Madsen, B., 1993) when the EUREF-BAL92 GPS campaign yielded class C accuracy $(5 \mathrm{~cm}$ at the time epoch of measurements) for the first ETRS89 realisation in the Baltic countries. The European Reference Frame is currently maintained through EPN (EUREF Permanent GNSS Network), which contains a number of national CORS of the European countries. A few European GNSS CORS belong also to the IAG Global Geodetic Observing System, which provides the geodetic infrastructure necessary for monitoring the Earth system and global change research (Kutterer, 2017). EPN is also instrumental in providing a connection between international and national coordinate systems, monitoring the stability and displacements of GNSS stations, whereas the EPN research products (coordinates, time-series, GNSS

${ }^{*}$ Corresponding author. E-mail: jaanus.metsar@maaamet.ee 
velocities, etc.) are used by various disciplines. The EPN permanent stations are divided into classes $\mathrm{A}$ and $\mathrm{B}$. Class $\mathrm{A}$ is assigned to stations with $1 \mathrm{~cm}$ position accuracy at all epochs of the time span of the used observations, class B indicates stations which position is with $1 \mathrm{~cm}$ of accuracy at the epoch of minimal variance of each station (Bruyninx et al., 2013).

Neighbouring to Estonia countries Sweden and Finland started to develop GNSS reference station networks early in the 1990-ies. The first CORS network in Sweden was established in 1993 and it consisted of 21 class A stations (Lilje, Wiklund, \& Hedling, 2014). Those stations became the backbone for the present SWEPOS - a network which consists of 400 reference stations, with station separation of $30-40 \mathrm{~km}$ in most parts of Sweden (see Lantmäteriet, 2018, for the current SWEPOS configuration). SWEPOS class A stations are built on solid bedrock and the antenna is installed on top of a $3 \mathrm{~m}$ high concrete pillar. All the equipment in class A stations is duplicated to ensure uninterruptable work. Other stations are mainly installed on buildings and are primarily foreseen for the RTN service, rather than monitoring the coordinate system distortions. The RTN service in SWEPOS was launched in 2004 and by 2009 the entire country was covered. (Lilje et al., 2014).

The first Finnish CORS network FinnRef consisting of 13 stations was established in 1995 . It was modernized and densified to 20 stations in 2012-2014. The resulting station separation in FinnRef was reduced to $100 \mathrm{~km}$ (see National Land Survey of Finland, 2018, for the current FinnRef configuration). Compared to SWEPOS, FinnRef is focused on monitoring the geodetic system of Finland, the provision of the RTN service is secondary. FinnRef stations are mounted on stable bedrock and the equipment is duplicated to overcome occasional station malfunctioning. The stability of FinnRef stations is monitored by time series analysis, via geometrical levelling and with total station measurements (Koivula, Laaksonen, Lahtinen, Marila, \& Kuokkanen, 2017).

Hence, the more-or-less similar size countries Finland and Sweden have adopted contrasting scenarios for the development of national GNSS CORS networks. Since these countries were also the GNSS CORS pioneers in the Baltic Sea region, then their experience is a valuable input for other countries at their efforts towards the establishment of national geodetic infrastructure, including GNSS CORS networks. The total area of Estonia is about $45000 \mathrm{~km}^{2}$. The area of Finland and Sweden is about $338000 \mathrm{~km}^{2}$ and $450000 \mathrm{~km}^{2}$ respectively. This yields that if Estonia would have blindly overtaken the FinnRef principles, then the bare minimum of GNSS CORS in Estonia would only be about 3-7. When following the example of SWEPOS however the bare minimum would be about 40 stations in Estonia. The optimal number of national GNSS CORS for Estonia however probably lays somewhere in the middle of this range.

Similarly to Finland and Sweden, Estonia is also located in a region with quite considerable post glacial land uplift (varies from $0 \mathrm{~mm} /$ year in South-East Estonia up to $3 \mathrm{~mm}$ /year in North-West Estonia). Land uplift is one of the reasons why GNSS reference stations are important for Estonia. GNSS time series help to assess the magnitude of land uplift and also horizontal plate movement, thus enabling to monitor (and account for) the deformations in geodetic systems.

Regarding the experiences of aforementioned countries, local conditions and rather limited resources, Estonia has developed and modernized its own GNSS CORS network - ESTPOS. This contribution gives a short overview about the establishment and modernization of Estonian GNSS reference station network. Firstly the initial stage (prior 2014) of geodetic networks and CORS in Estonia is briefly reviewed, which is followed by the modernization of the ESTPOS network. Then ESTPOS connection with Estonian national geodetic network and data usage is described. Comparisons are made with respect to the SWEPOS and FinnRef. Lastly an assessment on possible further ESTPOS developments is given and a brief summary concludes the paper.

\section{Geodetic GPS networks and the initial stage of GNSS CORS in Estonia}

In 1995 the structure of the national geodetic network was revised by the Estonian Land Board (ELB - a governmental agency responsible for the development and maintenance of geodetic networks in Estonia). A new national geodetic GPS network was constructed in 1996-1998, aiming at a more rigorous realisation of ETRS89 in Estonia (Rüdja, 1999). The markers of all (but one!) new geodetic points were ground-buried, with the average distance between adjacent I order GPS points of about 70-110 km. In 1997 static GPS measurements on 13 geodetic points of the I order network were carried out. The total length of the observing sessions for every baseline among the I order points was at least 48 hours, whereas 192 hours between I order geodetic points and the used reference stations (GNSS CORS of neighbouring countries). The data was processed with the Bernese GNSS Software in 1998 (Rüdja, 1999). A resolution of the EUREF Prague Symposium in 1999 approved the EUREF-Estonia-1997 results to correspond to the B class accuracy, i.e. about $\pm 1 \mathrm{~cm}$ at the epoch of observation (EUREF, 1999). Amongst the I order geodetic points was also the Suurupi GNSS CORS in Estonia. Since then GNSS reference stations have been an important part of Estonian geodetic system. Henceforth the development of GNSS reference stations in Estonia is described.

The first Estonian GNSS reference station SUR4 (initially denoted SUUR, the station name was updated due to slight location change in 2011) in Suurupi, was established in 1996 by ELB in cooperation with the Finnish Geodetic Institute (FGI). When choosing the location for SUUR, geological maps of the near Tallinn (the capital of Estonia) region were studied. Suurupi CORS was established in a 
lighthouse (Figure 1) that was built in 1760 . The foundation of Suurupi lighthouse is residing on limestone and thus it is presumably a very stable platform for a CORS. At first the Suurupi CORS was equipped with an FGI owned Ashtech Z-XII GPS receiver and an Dorne Margolin Choke Ring antenna. Since October of 2006 Suurupi GNSS reference station is also officially incorporated to EPN (Kollo \& Pihlak, 2008). Hence the current SUR4 is a part of continental and global GNSS solutions, and the data of SUR4 is freely downloadable from EPN.

A few years later more Estonian GNSS CORS were established. The next GNSS reference station was set up in 2006 on the rooftop of ELB's main building in Tallinn, Mustamäe. MUS2 (initially denoted MUST) was equipped with an Ashtech Z-XII GPS receiver and an Ashtech Geodetic GPS antenna. Additional 4 GNSS CORS were established in Tõravere (TOR2, initially denoted TORA), Kuressaare (KURE), Toila (TOIL) and Audru (AUDR), for their locations see Figure 2. The outdated equipment in SUR4 was also changed in 2007 by an Leica GRX1200GG PRO receiver and an Leica LEIAT504GG Choke Ring antenna. Hence altogether five GPS+GLONASS stations were functional in Estonia by 2007. Buildings chosen for mounting GNSS antennas were older than 30+ years. Later analysis of CORS time series have shown that the selected buildings appear to be stable enough and could be used for monitoring vertical land movement. The developed guidelines were used in later years for choosing locations for the rest of Estonian CORS.

In 2008 new CORS were set up in Kärdla (KARD), Mustvee (MVEE) and Võru (VOR2, initially denoted VORU) and outdated equipment in MUS2 was replaced. In those 4 new stations Leica System 500 GPS receivers and Leica GPS Choke Ring antennas LEIAT504 were used. Thus by the end of 2008 the first generation of ESTPOS, consisting of 9 operational GNSS reference stations, was accomplished (Figure 2). Station separation in the first generation of ESTPOS was about $70-100 \mathrm{~km}$ and this was

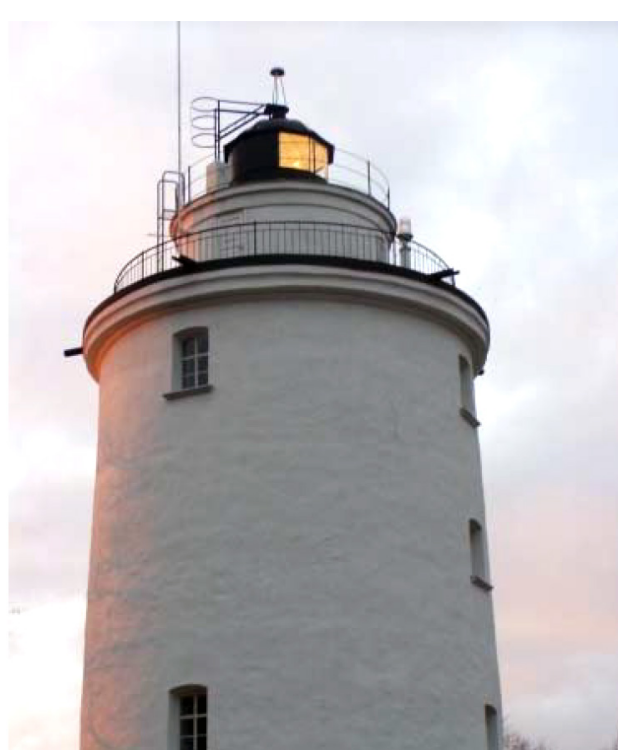

Figure 1. Suurupi lighthouse with the GNSS antenna mounted on the rooftop (Ellmann, 1997)

acceptable for monitoring the geodetic system, however not sufficient enough for high-quality RTN service.

The SUR4, TOR2, KURE, TOIL and AUDR GNSS reference stations are collocated with absolute gravimetry points, national geodetic points and levelling benchmarks. Also tide gauges are located near TOIL, KURE and AUDR. Having different types of geodetic networks merged in an optimum way provides the concept for an integrated geodetic network (Rüdja, 2002). In addition to SUR4 also KURE, TOIL and TOR2 reference stations became incorporated to EPN (Figure 3) in April of 2008.

\section{The 2014-2015 renovation of ESTPOS}

The inital ESTPOS CORS appeared to be located mainly near the outskirts of Estonia, leaving the inlands almost

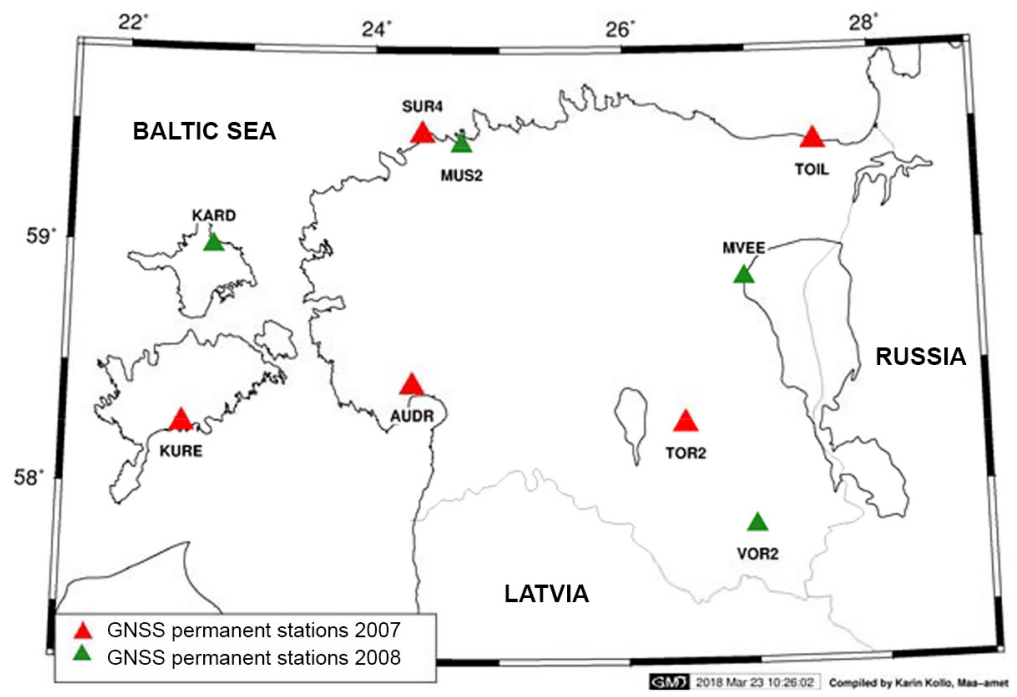

Figure 2. Estonian GNSS reference stations by the end of 2008 


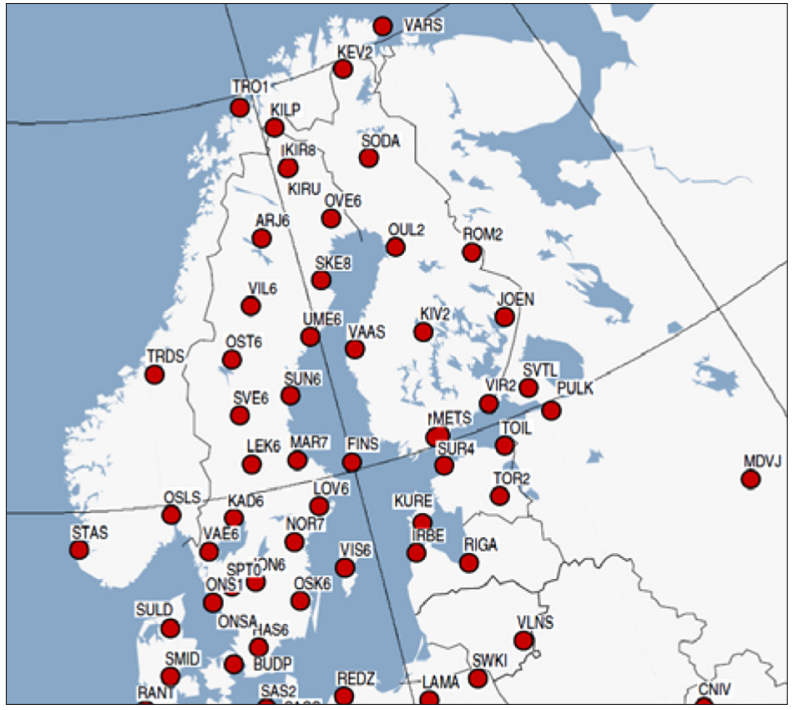

Figure 3. EPN stations in northern Europe (EPN, 2018 modif)

completely empty (see Figure 2). In comparison with FinnRef the distances between neighbouring CORS in Estonia were shorter, but considerably longer than that of SWEPOS.

Within the frames of an Estonian-Swiss co-operation program "Enhancing public environmental monitoring capacities", the ESTPOS network was significantly densified. The equipment of existing GNSS stations was modernized and 19 brand new stations were set up, bringing the total number of Estonian GNSS reference stations to 28 (Figure 4). Distances between CORS decreased to about $40-50 \mathrm{~km}$ and the network now covers the entire country more evenly. ESTPOS solutions also started to include FinnRef and LATPOS (Latvian national GNSS
CORS) networks and an GNSS CORS of the Estonian Maritime Administration. Hence, in addition to 28 ELB stations the ESTPOS solutions contain also 10 external reference stations. Such coverage enhances further the quality of positioning on the waterways and near-border areas of Estonia (Figure 4).

The equipment used in ESTPOS is now the same in all sites. Leica GR25 receivers and Leica AR25 Choke Ring antennas with LEIS domes are used (Figure 5 and Table 1). Hence, all of the ESTPOS stations are capable of receiving the Europe's GNSS Galileo signals. 14 new reference stations are also equipped with meteorological sensors Vaisala WXT520, which measure air temperature, humidity and pressure, wind speed and direction. Meteo data can be used to monitor weather conditions at the site and these data could also be used to assess the effects of local weather conditions on GNSS measurements. Presently meteo data are just collected and stored without any further inclusion to the GNSS related research.
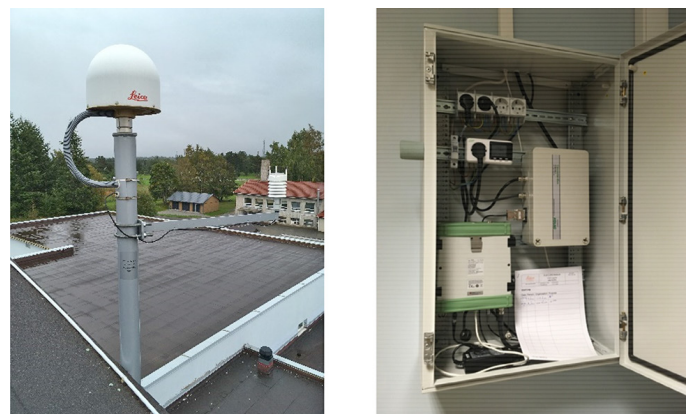

Figure 5. Typical installation of most ESTPOS stations - an AR25 Choke Ring radome antenna with the Vaisala WXT520 meteo sensor and an equipment housing containing a GR25 receiver and a converter for the meteo sensor

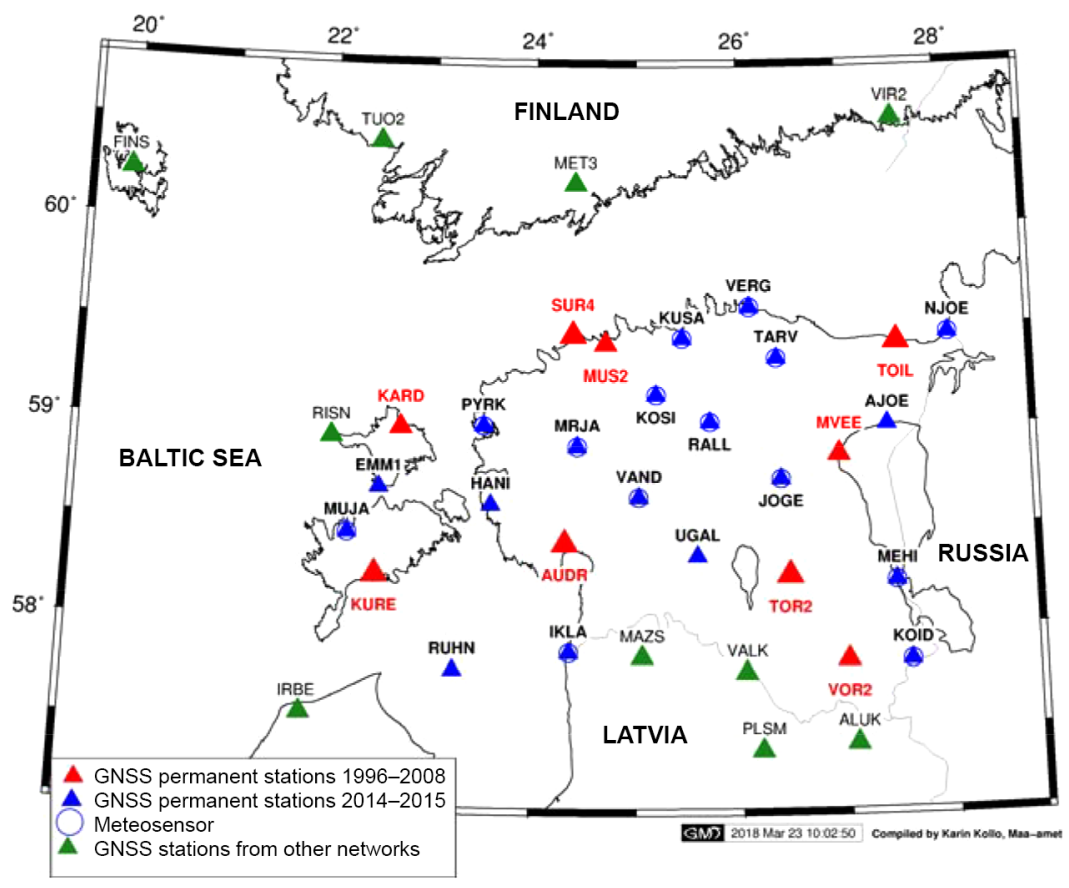

Figure 4. The modernized ESTPOS network (denoted by red and blue symbols) with external GNSS CORS (green triangles) 
Table 1. Overview of equipment changes in ESTPOS network

\begin{tabular}{|l|l|l|l|l|l|}
\hline & \multicolumn{1}{|c|}{1996} & \multicolumn{1}{|c|}{2006} & \multicolumn{1}{c|}{2007} & \multicolumn{1}{c|}{2008} & $4^{2}$ \\
\hline $\begin{array}{l}\text { No. of established } \\
\text { stations }\end{array}$ & \multicolumn{1}{|c|}{1} & 1 & \multicolumn{1}{c}{$5^{1}$} & $19^{3}$ \\
\hline Receiver type & Achtech Z-12 & Ashtech Z-12 & $\begin{array}{l}\text { Leica GRX1200GG } \\
\text { PRO }\end{array}$ & System 500 GPS & Leica GR25 \\
\hline Antenna type & $\begin{array}{l}\text { Dorne Margolin } \\
\text { Choke Ring }\end{array}$ & Ashtech Geodetic & $\begin{array}{l}\text { GPS + GLONASS } \\
\text { LEIAT504GG }\end{array}$ & $\begin{array}{l}\text { GPS Choke Ring } \\
\text { LEIAT504 }\end{array}$ & $\begin{array}{l}\text { AR25 GPS + } \\
\text { GLONASS Choke } \\
\text { Ring }\end{array}$ \\
\hline Satellite systems & GPS & GPS & GPS + GLONASS & GPS & $\begin{array}{l}\text { GPS + GLONASS + } \\
\text { Galileo }\end{array}$ \\
\hline $\begin{array}{l}\text { Total amount of } \\
\text { stations }\end{array}$ & 1 & 2 & 6 & 9 & 28 \\
\hline
\end{tabular}

${ }^{1}$ New equipment was also installed in SUR4.

${ }^{2}$ New receiver was also installed in MUS2. Antenna remained unchanged at first and a new LEIAT504 antenna was installed in 2012.

${ }^{3}$ Equipment was also changed in all previously established stations.

It is appropriate also to review the establishment of commercial GNSS CORS in Estonia. These are initiated and run by the Estonian re-sellers of major surveying instrument manufacturers. Accordingly, currently there are three commercial GNSS CORS networks/service providers - Trimble VRS NOW, HadNet and IVANET. Trimble VRS NOW network has 19 GNSS stations with Trimble receivers and antennas (see Geosoft, 2018, for more info). HadNet consists of 29 reference stations and uses Topcon equipment (see Topcon, 2018, for more info). IVANET is operated by a local Leica representative and it has 2 active GNSS reference stations on the basis of which RTK service is provided (see I.V.A. Leon, 2018, for more info). Therefore the 28 ESTPOS GNSS CORS are complemented by some 50 commercial CORS in Estonia.

\section{Interconnecting the I order geodetic network and ESTPOS}

Recall that Suurupi GNSS CORS belongs to the Estonian I order geodetic network (see Section 2). This comprises the basis of the Estonian national geodetic system. In 2008 the I order geodetic network was re-measured, whereas additional 6 GNSS reference stations were also incorporated to the campaign (Ellmann, Pihlak, \& Kollo, 2008). In the summer of 2017 the I order geodetic network was re-measured the second time, whereas all the operational ESTPOS stations were integrated to the measurements as well (Figure 6).

Note that the 1997, 2008 and 2017 GNSS campaigns were conducted during the years of Solar minimum. The durations of aforementioned campaigns are given in

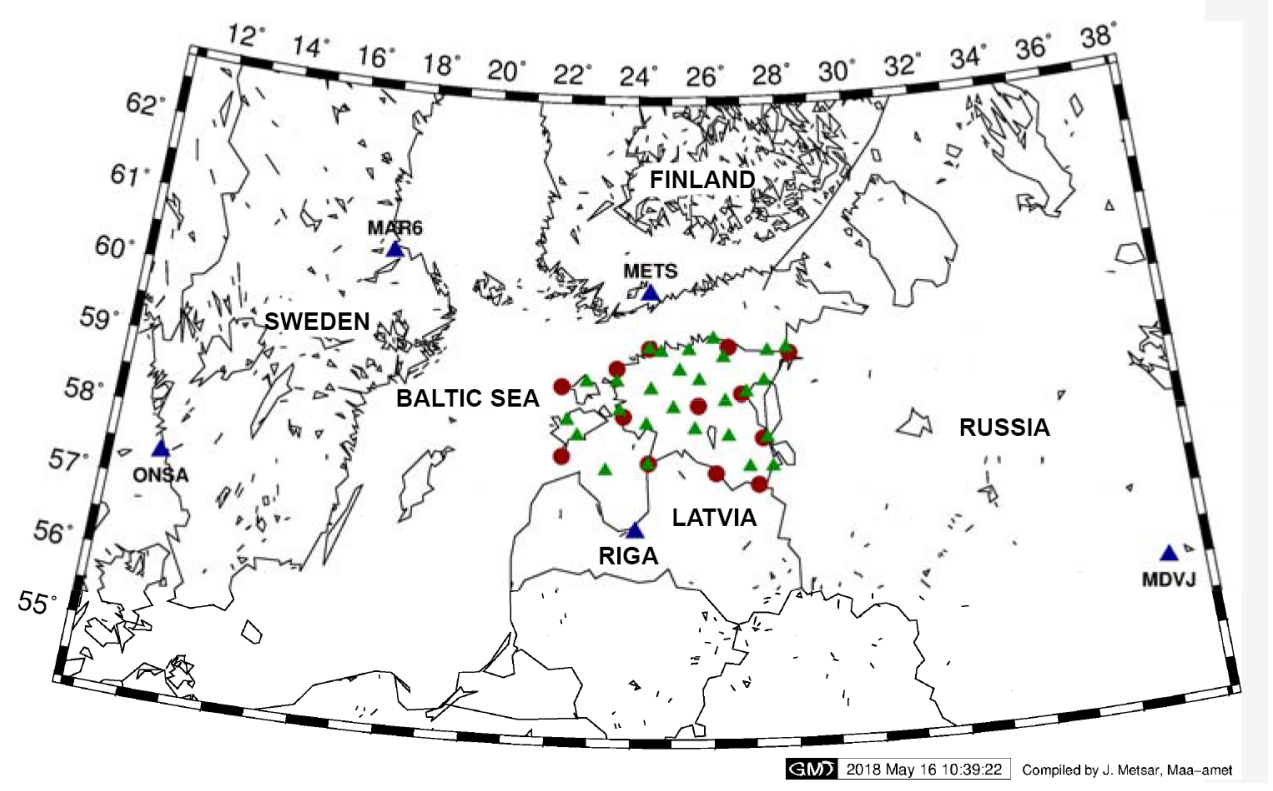

Figure 6. 2017 remeasurement campaign of Estonian I order geodetic points. Red - I order geodetic point, green ESTPOS GNSS reference station, blue - IGS (International GNSS Service) GNSS reference station used as fix point 
Table 2. Overview about the 2017 re-measurement campaign field work and the computations with Bernese software are documented in ELB's technical reports (Metsar \& Kollo, 2017; Metsar, Priit, \& Kollo, 2018). The final results of the 2017 re-measurement campaign will be presented for a forthcoming EUREF symposium.

Table 2. The durations of Estonian I order geodetic network measurements

\begin{tabular}{|c|c|}
\hline Campaign & Length of sessions \\
\hline $19-28.07 .1997$ & $72-216$ hours \\
\hline $28.07-08.08 .2008$ & $110-158$ hours \\
\hline $07-15.08 .2017$ & $84-175$ hours \\
\hline
\end{tabular}

The 2017 re-measurement campaign had two main goals - firstly to monitor the coordinate changes of the I order geodetic points and secondly to link ESTPOS GNSS reference stations with the Estonian national geodetic system. Starting from Jan. 01, 2018 the ESTPOS GNSS stations are officially imposed by an Estonian Ministry of Environment decree as a part of Estonian national geodetic system and they became hierarchically equal to Estonian national I order geodetic points. Alongside with the implementation of the European Vertical Reference System (EVRS, heights referred to the Normaal Amstardams Peil) and the corresponding EST-GEOID2017 model (Ellmann, Märdla, \& Oja, submitted) the ESTPOS is one of the corner-stones of the modern geodetic infrastructure in Estonia.

\section{The ESTPOS based weekly coordinate solutions}

Weekly SINEX (Solution INdependent EXchange format) solutions (coordinates) are routinely computed for all the Estonian GNSS CORS (including also commercial ones) since GPS week 1448 (Oct 7 2007). This is done in the ELB's Department of Geodesy by using Bernese GNSS
Software version 5.2. Also reference station stability and data quality is analysed regularly. All the stations are included in a monitoring system which uses weekly data to generate graphs depicting changes in station coordinates. Using these graphs the station quality is assessed and stations with bad or questionable data are removed from the weekly SINEX solutions. Reference station coordinates are computed in a global reference frame (IGS14) and transformed with Helmert 6-dimensional transformation into ETRF89 geocentric coordinates, geodetic coordinates and also local L-EST97 system 2D coordinates (Metsar, 2015).

Commercial GNSS CORS (see section 3) are included to the ELB's weekly computations to ensure that the coordinates of all Estonian GNSS reference stations would be compatible. Accurate GNSS CORS coordinates are important to assure high quality for the corrections of RTN services.

Estonian Land Board also participates in the Nordic Geodetic Commission's GNSS Analysis Centre. The ESTPOS CORS coordinate and troposphere weekly solutions are submitted there on weekly basis in order to unify reference frame related activities in the Nordic and Baltic countries (see e.g. Lahtinen et al., 2018).

\section{ESTPOS real time measurements}

Leica software GNSS Spider (Leica Geosystems, 2018) is used to run and monitor the ESTPOS network. The Spider software allows ELB to check the status and reset the receiver if needed; check and control the datastreams being sent from the GNSS stations; archive and send gathered GNSS data to the users and also assure that the RTN corrections are being sent to the rover users. Spider can identify problematic GNSS reference stations and users working in the field in real time (Figure 7).

The most important advantage of the reconstructed ESTPOS is the RTN possibility. To calculate and transmit

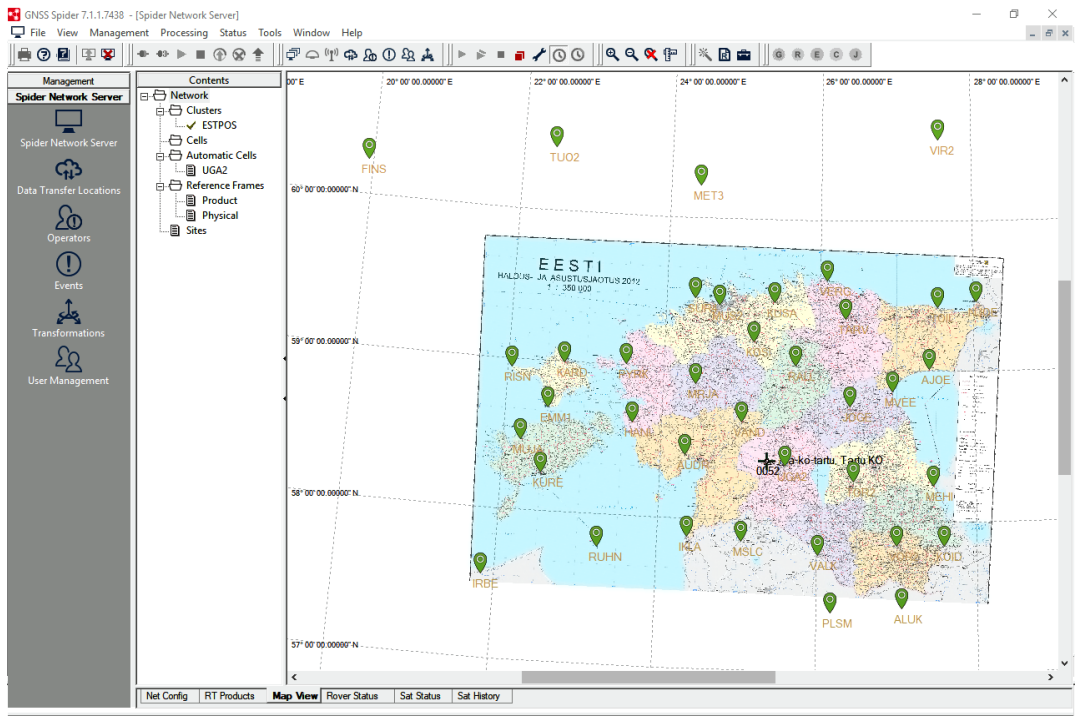

Figure 7. Screenshot of the Leica GNSS Spider Network Server, which shows the locations of GNSS reference stations and their status (green - operational, red - problematic).

Also info about RTN users (black cross) is shown - connection status and the used corrections method 
the GNSS corrections mainly MAX (Master Auxiliary Corrections) method is used. With the MAX option the Spider software chooses 6 reference stations closest to the rover and calculates the needed corrections. Corrections to the rover are however given with respect to the closest reference station (aka Master Station). This way the coordinates of the rover are given with respect to a certain (often the closest one) physical reference station, not a virtual station as is done in VRS (Virtual Reference Station, for the principles see Landau, Vollath, \& Chen, 2002). In addition to MAX, the ESTPOS also supports VRS, iMAX (Individualized Master Auxiliary Corrections) and FKP (Flächen-Korrektur Parameter) methods (Leica Geosystems, 2008).

The quality of RTN service in ESTPOS network appears to be satisfactory. Verification measurements have shown that the accuracy of RTN is $1-2 \mathrm{~cm}$ in horizontal and $2-3 \mathrm{~cm}$ in vertical components. Empirical studies (e.g. Kirs, 2017) confirm that the accuracy of ESTPOS is better than in other local commercial networks. Estonia is also covered very well (almost $100 \%$ of the territory) with mobile data communication, which enables comfortable RTN usage all over the country.

\section{ESTPOS usage}

ESTPOS RINEX (Receiver INdependent EXchange format) data for post-processing purposes is freely downloadable for anyone. Access to ESTPOS RTN service and data is not open for commercial use, but is authorised to certain Estonian government and academic institutions: Estonian Maritime Administration, Estonian Environment Agency, Estonian Agricultural Registers and Information Board, Tallinn University, Tallinn University of Technology, Estonian University of Life Sciences, etc. Reference station RINEX data are also shared with co-operating international partners from Finland, Latvia, EPN, Pulkovo Astronomical Observatory, University of Nevada, etc.

There are several applications for the ESTPOS services. For instance ELB's Department of Geodesy uses ESTPOS data for routine geodetic measurements, both in static and RTN mode. The GNSS time series have specified the land uplift velocities in the Baltic Sea region (Metsar, Kollo, \& Ellmann, 2016). The ELB's Department of Photogrammetry uses GNSS reference station data to calculate trajectories for their photogrammetric and airborne laser scanning mapping flights. ELB's Department of Land Cadastral division however uses ESTPOS RTN service in cadastral surveys.

\section{Further ESTPOS developments}

The Estonian EPN stations SUR4, KURE, TOIL and TOR2 are considered as the ESTPOS fundamental stations. All the equipment should be duplicated in those stations and the antenna pillar should be mounted directly on the ground, not on a building as it is at the moment. In the near future the TOR2 antenna will be relocated from its present location and that gives a reasoning to establish it by following the examples of our neighbours (see section 1). If it proves to be a feasible solution then the same could be done in KURE and TOIL also (no need for SUR4 as the lighthouse has proven to be stable enough, see section 2).

The stability of ESTPOS stations could be checked with total stations or precise levelling as is done in Finland (see section 1). Because almost all ESTPOS stations are on top of high buildings, precise levelling would be too complicated though. Trigonometric levelling would however give an opportunity to check the quality of GNSS time series.

The amount of GNSS stations in ESTPOS seems to be optimal. 28 GNSS stations yields that Estonia has roughly 1 national GNSS station per $1600 \mathrm{~km}^{2}$. The corresponding numbers in Sweden and Finland are about $1100 \mathrm{~km}^{2}$ and $17000 \mathrm{~km}^{2}$. This means that the density of ESTPOS stations is almost the same as the density of SWEPOS. According to Koivula et al. (2017) in the coming years 20-30 additional FinnRef stations are planned to establish, yielding thus an average station separation further down to $50-70 \mathrm{~km}$ in Finland.

The SWEPOS shares its infrastrucuture with local commercial service providers to ensure that the results for all the users would be compatible. This is also likely the most cost-effective solution for the country as a whole (Lilje et al., 2014). In Estonia there are 3 commercial networks and service providers at the moment (see section 3). If all three service providers started to co-operate with ESTPOS and share their infrastructure then the total number of GNSS reference stations would roughly triple (70-80) and the coverage of Estonia would be much more dense. The current business interests of the commercial enterprises do not support this idea, though. However according to the Swedish example, the service providers would not compete, but rather complement each other (Lilje et al., 2014).

\section{Conclusions}

Modernized ESTPOS is an important part of Estonian geodetic reference system. The equipment and the software used are modern and capable of solving the present technological challenges. Compared to other similar networks, ESTPOS is dense and its RTN service has proven to be fully functional. As for the future of ESTPOS, there is no apparent need to establish much more reference stations (except maybe a few new sites in troublesome regions). Instead ESTPOS should concentrate on making the existing GNSS reference stations better and develop the infrastructure surrounding the sites - stable internet connectivity, fluent dataflow, power supplies in case of emergencies, etc. It may be needed because in the near future ESTPOS possibilities might find usage in the development and use of unmanned vehicles, road toll service and in other applications relying on accurate real time positioning information. 


\section{Acknowledgements}

The Estonian-Swiss co-operation program "Enhancing public environmental monitoring capacities" contributed significantly to the construction of the ESTPOS network.

\section{References}

Bruyninx, C., Altamimi, Z., Caporali, A., Kenyeres, A., Legrand, J., \& Lidberg, M. (2013). Guidelines for EUREF densifications. Retrieved from http://www.epncb.oma.be/_documentation/guidelines/Guidelines_for_EUREF_Densifications.pdf

Ellmann, A. (1997). Suurupi GPS püsivaatlusjaam [Suurupi GPS reference station]. Geodeet, nr. 12.

Ellmann, A., Märdla, S., \& Oja, T. (submitted). The $5 \mathrm{~mm}$ geoid model for Estonia computed by the least squares modified Stokes formula. Submitted to Survey Review.

Ellmann, A., Pihlak, P., \& Kollo, K. (2008). Kõrgtäpsed GPSmõõtmised riigi geodeetilise põhivõrgu aluspunktidel 2008. aasta suvel [GPS remeasurement campaing on national geodetic points in the summer of 2008]. Geodeet, nr. 37.

EPN. (2018). EPN Tracking network. Retrieved from http://www. epncb.oma.be/images/maps/EUREFDL.pdf

EUREF. (1999). Symposia - Resolutions. Prague, 2-5 June 1999. Retrieved from http://www.euref.eu/html/ resolutions_ prague1999.pdf

Geosoft. (2018). Trimble VRS Now. Retrieved from http://www. geosoft.ee/tutvustus

I.V.A. Leon. (2018). IVANET. Retrieved from http://www.ivaleon.ee/ivanet/

Kirs, E. (2017). Eesti RTK GNSS võrkude täpsuse hindamine [Accuracy evaluation of RTK GNSS networks in Estonia]. Tartu.

Koivula, H., Laaksonen, A., Lahtinen, S., Marila, S., \& Kuokkanen, J. (2017). Finnish permanent GNSS network, FinnRef. Retrieved from https://www.fig.net/resources/proceedings/ fig_proceedings/fig2017/ppt/ts07c/TS07C_koivula_laaksonen_et_al_8939_ppt.pdf

Kollo, K., \& Pihlak, P. (2008). Ülevaade geodeetiliste põhivõrkude töödest 2007-2008 [Overview of works done on national geodetic networks in 2007-2008]. Geodeet, nr. 37.

Kutterer, H. (2017). GGOS - The global geodetic observing system of the International Association of Geodesy (IAG). Retrieved from http://www.fig.net/resources/proceedings/fig_proceedings/fig2017/papers/ts03c/ TS03C_kutterer_9127.pdf

Lahtinen, S., Pasi, H., Jivall, L., Kempe, C., Kollo, K., Kosenko, K., Pihlak, P., Prizginiene, D., Tangen, O., Weber, M., Paršeliunas, E., Baniulis, R., \& Galinauskas, K. (2018). First results of the Nordic and Baltic GNSS Analysis Centre. Journal of Geodetic Science, 8(1).

https://doi.org/10.1515/jogs-2018-0005

Landau, H., Vollath, U., \& Chen, X. (2002). Virtual reference station systems. Journal of Global Positioning Systems, 1(2), 137-143. https://doi.org/10.5081/jgps.1.2.137

Lantmäteriet. (2018). SWEPOS. Retrieved from https://swepos. lantmateriet.se/
Leica Geosystems. (2008). RTK Networks - different methods. System 1200 Newsletter, No. 53, BU surveying, surveying \& engineering division, pp. 1-6.

Leica Geosystems. (2018). Leica GNSS Spider. Retrieved from https://leica-geosystems.com/products/gnss-reference-networks/software/leica-gnss-spider

Lilje, M., Wiklund, P., \& Hedling, G. (2014). The use of GNSS in Sweden and the national CORS network SWEPOS. Retrieved from https://www.lantmateriet.se/globalassets/kartor-ochgeografisk-information/gps-och-matning/geodesi/rapporter_ publikationer/publikationer/fig2014_ts08a_lilje_wiklund_et_ al_7019.pdf

Madsen, F., \& Madsen, B. (1993). A new GPS-network in the Baltic Countries. In E. Gubler, H. Hornik (Eds), Report on the Symposium of the IAG Subcommission for European Reference Frame (EUREF) held in Budapest, 17-19 May 1993, Veröff. Bayr. Komm. Intern. Erdmessung. EUREF Publ. No. 2, München, pp. 83-91.

Metsar, J. (2015). Riiklik GNSS püsijaamade võrk, selle aegridade kasutamine jääajajärgse maatõusu täpsustamisel [National GNSS reference station network, using its time series for specifying post-glacial land uplift]. Tallinn.

Metsar, J., \& Kollo, K. (2017). Riigi geodeetilise võrgu I klassi kordusmõõtmised 2017 [Remeasurement campaing of first order national geodetic network in 2017]. Estonian Land Board.

Metsar, J., Kollo, K., \& Ellmann, A. (2016). GNSS aegridade kasutamine jääajajärgse maatõusu täpsustamisel [Using GNSS reference station time series for specifying post-glacial land uplift]. Geodeet, nr. 45/46.

Metsar, J., Priit, P., \& Kollo, K. (2018). Riigi geodeetilise põhivõrgu I klassi kordusmõõtmiste arvutused [Computations of first order geodetic network remeasurement campaign]. Estonian Land Board.

Moser, V., Barišić, I., Rajle, D., \& Dimter, S. (2016). Comparison of different survey methods data accuracy for road design and construction. In $4^{\text {th }}$ International Conference on Road and Rail Infrastructure - CETRA 2016. Šibenik, Croatia.

National Land Survey of Finland. (2018). FinnRef GNSS Stations. Retrieved from https://www.maanmittauslaitos.fi/en/ research/research/other-research-and-measuring-stations/ finnref-gnss-stations

Rüdja, A. (1999). A new ETRS89 system for Estonia. Report on the Symposium of the IAG Subcomission for the European Reference Frame (EUREF) held in Prague 2-5 June 1999. Veröff. Bayr. Komm. Intern. Erdmessung. EUREF Publ. 8. München, pp 123-135.

Rüdja, A. (2002). Integrated Georeference of Estonia. In Proceedings of the $14^{\text {th }}$ General Meeting of the Nor dic Geodetic Commission. 1-5 October 2002. Espoo, Finland, Kirkonummi, pp. 201-210.

Sobak, M., Ellmann, A., Mill, T. (2015). Terrestrial laser scanning assessment of generalization errors in conventional topographic surveys. Geodesy and Cartography, 41(1), 15-24. https://doi.org/10.3846/20296991.2015.1029755

Topcon. (2018). HadNet. Retrieved from http://www.topcon.ee/ 